\title{
Treating the patient and not just the cancer: therapeutic burden in prostate cancer
}

\author{
Daniel E. Spratt $\mathbb{D}^{1} \cdot$ Neal Shore $^{2} \cdot$ Oliver Sartor $\mathbb{B}^{3} \cdot$ Dana Rathkopf $^{4} \cdot$ Kara Olivier $^{5}$
}

Received: 5 September 2020 / Revised: 12 January 2021 / Accepted: 20 January 2021 / Published online: 18 February 2021

(c) The Author(s) 2021. This article is published with open access, corrected publication 2021

\begin{abstract}
Background Prostate cancer (PC) is a leading cause of death in older men. Androgen deprivation therapy (ADT) is considered the standard-of-care for men with locally advanced disease. However, continuous androgen ablation is associated with acute and long-term adverse effects and most patients will eventually develop castration-resistant PC (CRPC). The recent approval of three, second-generation androgen receptor inhibitors (ARIs), apalutamide, enzalutamide, and darolutamide, has transformed the treatment landscape of PC. Treatment with these second-generation ARIs have produced positive trends in metastasis-free survival, progression-free survival, and overall survival. For patients with non-metastatic CRPC, who are mainly asymptomatic from their disease, maintaining quality of life is a major objective when prescribing therapy. Polypharmacy for age-related comorbidities also is common in this population and may increase the potential for drug-drug interactions (DDIs).

Method This review summarizes the multiple factors that may contribute to the therapeutic burden of patients with CRPC, including the interplay between age, comorbidities, concomitant medications, the use of ARIs, and financial distress.

Conclusions As the treatment landscape in PC continues to rapidly evolve, consideration must be given to the balance between therapeutic benefits and potential treatment-emergent adverse events that may be further complicated by DDIs with concomitant medications. Patient-centered communication is a crucial aspect of alleviating this burden, and healthcare professionals (HCPs) may benefit from training in effective patient communication. HCPs should closely and frequently monitor patient treatment responses, in order to better understand symptom onset and exacerbation. Patients also should be encouraged to participate in exercise programs, and health information and support groups, which may assist them in preventing or mitigating certain determinants of the therapeutic burden associated with PC and its management.
\end{abstract}

\section{Introduction}

Worldwide, older populations continue to grow at an unprecedented rate. By 2030 , it is projected that nearly $12 \%$ of the global population will be aged 65 years or older [1]. Conventionally, a person in this age range is referred to as "elderly" [2]. However, chronology alone may not reliably

Daniel E. Spratt

sprattda@med.umich.edu

1 Michigan Medicine, Ann Arbor, MI, USA

2 Carolina Urologic Research Center, Atlantic Urology Clinics, Myrtle Beach, SC, USA

3 Tulane University School of Medicine, New Orleans, LA, USA

4 Memorial Sloan Kettering Cancer Center, New York, NY, USA

5 Massachusetts General Hospital Cancer Center, Boston, MA, USA predict the rate of physiological decline owing to environmental factors and comorbidities. Differences in genetics, lifestyle, and overall health status suggest a heterogeneity to the aging process. It is important to consider such diversity, particularly with respect to the individualization of treatment regimens [3].

Prostate cancer (PC) develops predominantly in older patients with an average age at diagnosis of 66 years [4]. Older patients may be more likely to experience aggressive forms of the disease compared with their younger counterparts. However, studies of the subset of men aged $<50$ years diagnosed with advanced PC provide strong evidence of poor survival in this younger age group [5]. The association between age and PC aggressiveness has been confirmed in several prospective and retrospective studies [6-8]. PC is the fifth leading cause of cancer-related death in men worldwide [9], with an incidence rate of $\sim 60 \%$ in 
men aged older than 65 years [10] and an estimated 33,330 deaths in 2020 , representing $~ 10 \%$ of all male deaths [11].

Androgen deprivation therapy (ADT) is the standard-ofcare for patients with advanced PC [12]. Although proven to be efficacious, ADT is associated with acute and longterm drug-related adverse effects. Many patients with rising prostate-specific antigen (PSA) levels eventually progress to castration-resistant PC (CRPC), often associated with persistent androgen receptor (AR) signaling, despite maintaining castrate concentrations of serum testosterone, defined as $<50 \mathrm{ng} / \mathrm{dL}[13,14]$.

This review aims to discuss the potential clinical impact of the interplay between age, comorbidities, concomitant medications, and second-generation androgen receptor inhibitors (ARIs) on the therapeutic burden of patients with CRPC. In the context of this review, we define therapeutic burden as the clinical impact on patients from the intersecting factors of adverse events (AEs), drug-drug interactions (DDIs), chronic comorbidities, polypharmacy, financial burden, and the involvement of multiple healthcare professionals (HCPs) in patient management.

\section{Factors defining therapeutic burden}

Therapeutic burden is typically defined as the workload of healthcare and its impact on patient functioning and wellbeing. The "workload" includes the demands on patient time and energy owing to treatment, including understanding prescribed or administered therapies, attending appointments, arranging supportive services, and adhering to a medication schedule. The "impact" on patient function includes the effect of the workload on the behavioral, cognitive, physical, and psychosocial wellbeing of the patient $[15,16]$.

The interdependent components that contribute to therapeutic burden include polypharmacy, AEs, chronic comorbidities, long-term concomitant medications, and suboptimal communication between patients and HCPs [16]. Increased therapeutic burden is associated with poor treatment compliance, wasted resources, and suboptimal clinical outcomes [17]. Therefore, these factors should be considered when adding ARIs to ongoing ADT and patientcentric treatment selections should be prioritized whenever possible.

\section{Communication between patients and HCPs}

Barriers to communication between patients and HCPs might also contribute to the therapeutic burden of patients with PC. For example, patients may believe that they cannot effectively describe their symptoms as they lack the appropriate vocabulary. Building a patient-focused relationship based on individual and family needs strengthens trust and mutual engagement throughout the cancer journey.

Patient-centered communication is particularly important when developing a care plan: allaying fears, managing pain, and adverse treatment effects, as well as the timely referral to hospice for end-of-life care [18]. Patient-centered communication with HCPs has been associated with better health-related quality of life (HRQoL) [19], emphasizing the importance of open, bidirectional dialog.

Insufficient patient-centered information on treatment, access to, and coordination of care are among the most notable perceived deficiencies in patient experience with cancer care [20, 21]. Studies have found that clinicians request patient preferences in medical decisions only $~ 50 \%$ of the time $[22,23]$. Furthermore, patients who felt more involved in the decision-making process were likely to feel more confident in their decisions [23].

Communication between the HCP and the primary caregiver is equally valuable. Partners or caregivers contribute importantly to disease management and are major providers of emotional support, which may adversely affect their own health and quality of life (QoL) [24]. Partners of patients with $\mathrm{PC}$ also report greater degrees of emotional distress than the patients themselves, as personal health issues increase, with a prevalence of anxiety and depression reported in $\sim 47 \%$ and $42 \%$, respectively [24-26]. Coherent communication with HCPs could help identify positive coping strategies for the primary caregiver and possible interventions to facilitate communication among couples navigating PC treatment [25].

Clinicians may lack sufficient formal training in communication, which affects recognition of and response to the informational and emotional needs of the patient [18]. In addition, opportunities exist to better harmonize communication among HCPs by aligning electronic healthcare records across interdisciplinary care [27].

\section{Financial burden of PC}

"Financial toxicity" is becoming a familiar term used in the discussion of cancer therapies. Defined as the objective financial burden and subjective financial distress of patients with cancer, as a result of innovative drug treatment and concomitant health services, financial distress for patients with PC is not isolated from the overall anxiety and discomfort experienced as a result of a cancer diagnosis and its ensuing therapeutic interventions [28].

Financial toxicity has been described as a corollary to cancer treatment akin to nausea and hair loss [28]. The combination of emotional distress and financial obligations associated with cancer care may impede the ability of the patient to cope effectively with the disease, its symptoms and its treatment thereby adversely affecting health 
outcomes. In the context of patient-centered cancer care, the clinician also can assist in containing the financial burden and distress to an individual patient with cancer. In 2017, The American Cancer Society developed a list of questions on cost-of-care that patients diagnosed with cancer might wish to pose to their HCP and which might facilitate the urgent dialog on avoiding low-value treatment while pursuing concrete solutions to preserve financial health [28].

The application of validated instruments, such as the COmprehensive Score for financial Toxicity (COST) measure, to sensitive discussions of treatment affordability with the patient, may assist the clinician to better explore and appreciate individual spending habits, financial resources and, psychosocial responses of the patient with cancer to financial burden [29]. Other commonly employed, multidimensional HRQoL instruments fail to capture the "social impact" of serious disease, treatment, and financial variables. The early literature demonstrates that issues can span the range of employment, activities of daily living, and finances while later works continue to expose the social issues of significant concern for patients with cancer. Both qualitative research and economic evaluations have illustrated that financial worry and hardship are both evident and prevalent in this patient population [30].

The initial treatment and subsequent monitoring of patients with PC places a heavy burden on the US healthcare system. The average per-patient lifetime cost of PC treatment averages $\sim \$ 34,000$ and PC-related costs represent up to one-third of total medical care depletion [31]. Studies also have indicated a stage effect of PC on the cost of treatment, escalating incrementally as patient risk increases. The aging population of patients with PC will augment the clinical and economic burden of PC on the healthcare system and, therefore, the choice of initial treatment could potentially limit healthcare expenditures and resources [32].

\section{Comorbid conditions}

Chronic comorbid conditions commonly occur among older men with $\mathrm{PC}$, with $>50 \%$ having at least one pre-existing chronic condition, the most prevalent being cardiometabolic and chronic respiratory diseases or disorders [27, 33].

In those patients who live with numerous, non-malignant comorbid conditions, increased drug burden often can be associated with diminished physical function, attention, concentration, and medication non-adherence [27]. Furthermore, comorbidity patterns involving cardiovascular, metabolic diseases, mental illness, and musculoskeletal disorders have been linked to diminished HRQoL [34].

When electing to add an ARI to ongoing ADT, HCPs should base their selection on the approved indication, proven efficacy, drug safety and tolerability, life expectancy with respect to curative intent, accessibility to medication, cost-of-drug, patient preference, HRQoL, and available psychosocial support, as well as the more global effects of DDIs associated with polypharmacy $[35,36]$. Cross comparisons of comorbidity impact on survival outcomes in patients with PC is challenged by the heterogeneity of study designs and assessment techniques [37]. A standardized, patient-centric, quantitative measure of multimorbidity, that may be applied readily in both research and clinical practice is needed, to better characterize the growing population of patients with comorbid conditions [38].

\section{AR-targeted therapeutic options for PC}

Biochemical recurrence is experienced by $27-53 \%$ of patients who have previously undergone either prostatectomy or radiotherapy [12]. Resistance mechanisms to ADT treatment have been associated primarily with aberrant AR signaling [39]. These mechanisms contribute to neoplastic cellular proliferation and tumor progression to CRPC [14, 40].

CRPC is defined by a rising PSA concentration and/or radiographical progression despite a castrate serum testosterone level $<50 \mathrm{ng} / \mathrm{dL}$. In the castration-resistant patient, metastases detected by conventional imaging with computerized tomography or technetium-99m scintigraphy is defined as metastatic CRPC (mCRPC), whereas CRPC without radiographic evidence of metastases is categorized as non-metastatic CRPC (nmCRPC) [12, 13].

Since 2012, the treatment landscape for CRPC in the US has been transformed following the approval of abiraterone acetate/prednisone (approved for mCRPC) [41] and the second-generation ARIs [42] enzalutamide (approved for mCRPC and nmCRPC), apalutamide (approved for nmCRPC), and darolutamide (approved for nmCRPC) [43-45]. Ongoing and future clinical trials are expected to broaden the indications for ARIs to earlier stages of PC, possibly including the neoadjuvant setting [46, 47].

Although ADT is generally well tolerated, androgen depletion may exert negative effects on cognitive function, cardiovascular health, sexual health, insulin sensitivity, and bone health (including falls and fracture) [48, 49]. Therefore, clinicians should consider how ARI-related toxicities may affect patients with PC and chronic comorbidities managed with long-term concomitant medication, and how multiple interdependent factors might contribute to the therapeutic burden of CRPC.

\section{Clinical profiles of second-generation ARIs for CRPC}

Enzalutamide, apalutamide, and darolutamide were approved based on significant improvements in both overall 
survival (OS) and metastasis-free survival (MFS) versus placebo in phase 3 clinical trials (Table 1).

\section{Enzalutamide}

In the PROSPER trial of patients with nmCRPC, enzalutamide plus ongoing ADT demonstrated significantly improved median MFS, reduced risk of radiographic progression or death, prolonged times to first use of new antineoplastic therapy, and PSA progression compared with placebo plus ADT [50]. In the final analysis of PROSPER, enzalutamide also was associated with significantly prolonged OS [51]. In chemotherapy-naive patients with mCRPC in PREVAIL, treatment with enzalutamide was associated with significantly improved OS compared with placebo [52]. In the AFFIRM trial, enzalutamide also was associated with significantly prolonged post-chemotherapy OS versus placebo in patients with mCRPC [53].

\section{Apalutamide}

In the SPARTAN trial, apalutamide plus ADT was associated with significant improvements in median MFS, progression-free survival (PFS), time to metastasis, and time to symptomatic progression compared with placebo plus ADT in patients with nmCRPC [54]. Apalutamide also was associated with significantly prolonged $\mathrm{OS}$ in the final analysis of the SPARTAN trial [55].

\section{Darolutamide}

In the ARAMIS trial, darolutamide plus ADT was associated with significantly longer median MFS compared with placebo plus ADT in patients with nmCRPC. Darolutamide also was associated with improvements in the secondary endpoints including OS, time to pain progression, time to cytotoxic chemotherapy, and time to a symptomatic skeletal event [56, 57]. In the final analysis of ARAMIS, darolutamide was associated with a significant improvement in OS compared with placebo, although median OS was not reached in either treatment group [57].

\section{Safety profiles}

Maintained QoL and physical wellbeing are important considerations when treating patients with CRPC. Given the negative impact that treatment-emergent AEs can impose on QoL and their association with increased healthcare utilization and cost, therapeutic efficacy and response must always be balanced against the potential risk of amplifying treatment burden by impairing functional capacity and exacerbating comorbid symptoms [58]. Evidence from several clinical trials has confirmed an increased incidence of certain AEs associated with apalutamide or enzalutamide added to ADT versus placebo plus ADT (Table 1).

\section{Enzalutamide}

In PROSPER, the AEs associated with enzalutamide at an incidence of $>10 \%$ compared with placebo included fatigue, hot flashes, nausea, falls, dizziness, decreased appetite, major cardiovascular events, and hypertension [50]. Similarly, in AFFIRM, a higher incidence of all grades of fatigue, diarrhea, hot flashes, musculoskeletal pain, and headache was reported with enzalutamide compared with placebo [53]. PREVAIL reported a higher incidence of falls in the overall population (12 vs $5 \%$ ), as well as in the subgroup of patients aged $\geq 75$ years (19 vs 8\%) with enzalutamide versus placebo, respectively [52, 59].

In clinical trials, increased risk of seizure with enzalutamide has been observed in association with higher than recommended daily doses of $160 \mathrm{mg}$, or with concomitant medications or conditions [53, 60], which suggests the potential for enzalutamide to affect the central nervous system (CNS) [61].

\section{Apalutamide}

In SPARTAN, AEs associated with apalutamide that occurred at an incidence $\geq 15 \%$ compared with placebo included fatigue, rash, falls, mental impairment, and hypothyroidism [54].

\section{Darolutamide}

As darolutamide has only recently been approved, its published AE profile is limited to the pivotal ARAMIS phase 3 trial. The available data indicate that the safety profile of darolutamide reflects minimal increases in AEs of any grade beyond that of background ADT, with the exception of fatigue which was reported more frequently with darolutamide than with placebo [56]. No differences were reported between the two treatment arms in the incidence of falls, cognitive disorder, hypertension, and hypothyroidism [56]. In the final analysis of the ARAMIS trial, darolutamide was associated with minimal or no difference in the incidence of most ARI-related AEs, including falls, fractures, hypertension, rash, and mental impairment. Fatigue was the only $\mathrm{AE}$ with an incidence higher than $10 \%$ observed with darolutamide [57].

Darolutamide demonstrated low blood-brain barrier penetration in rodents, supported by a human neuroimaging study, which may be associated with a reduced risk of CNS AEs [56, 62-65]. Given that darolutamide was approved in 2019 for the treatment of nmCRPC, these results require confirmation with expanded safety data. 


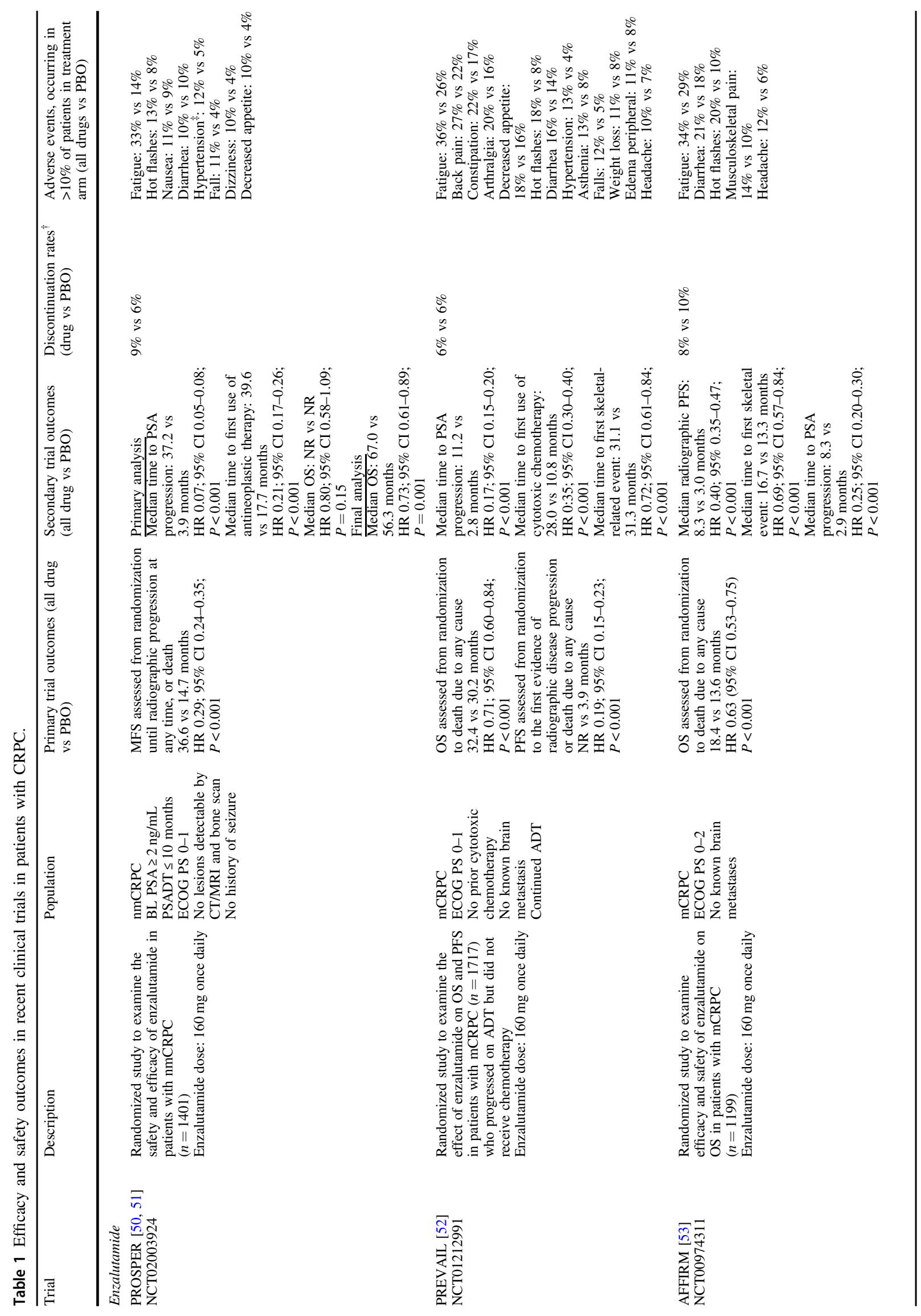




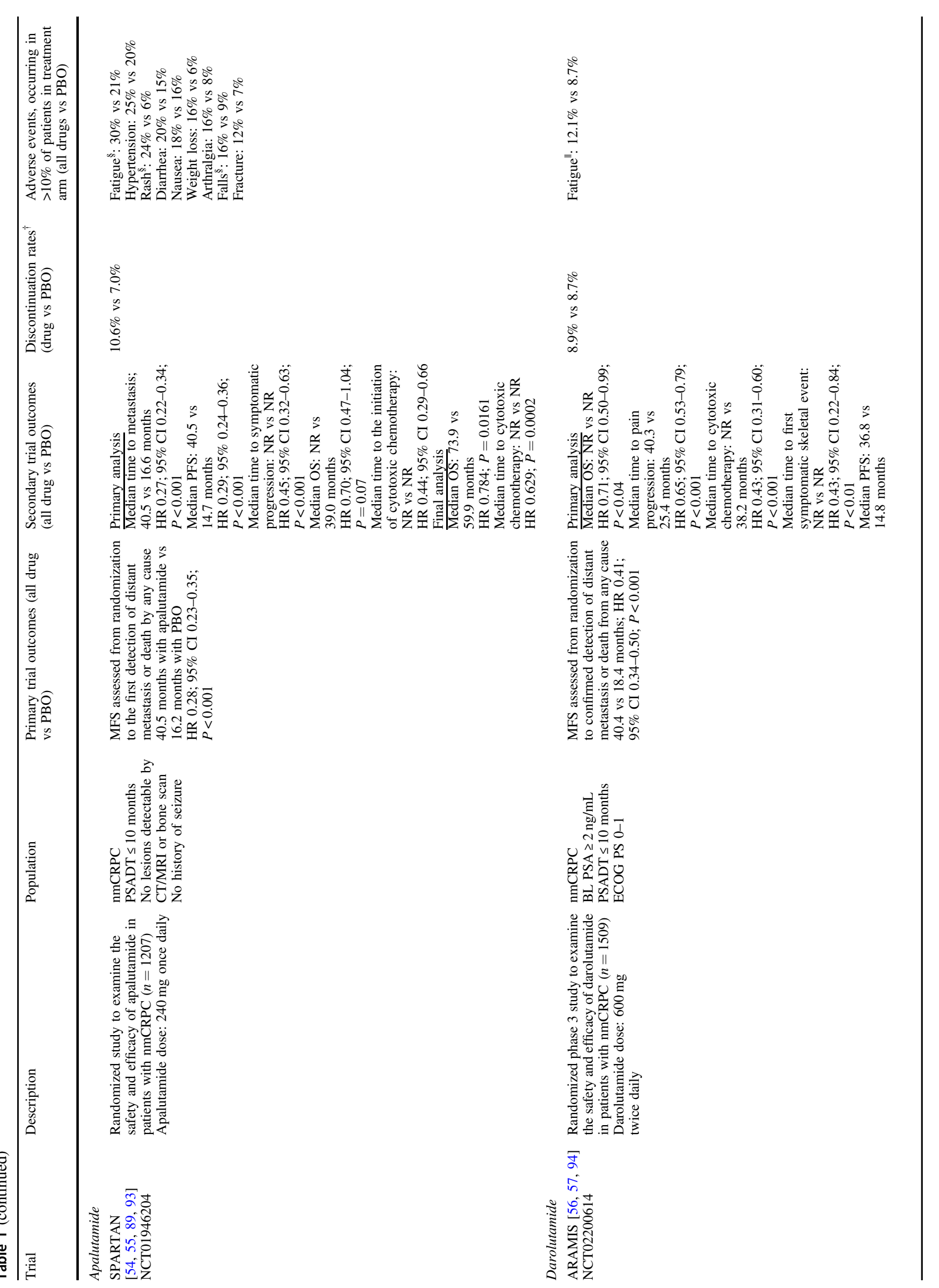




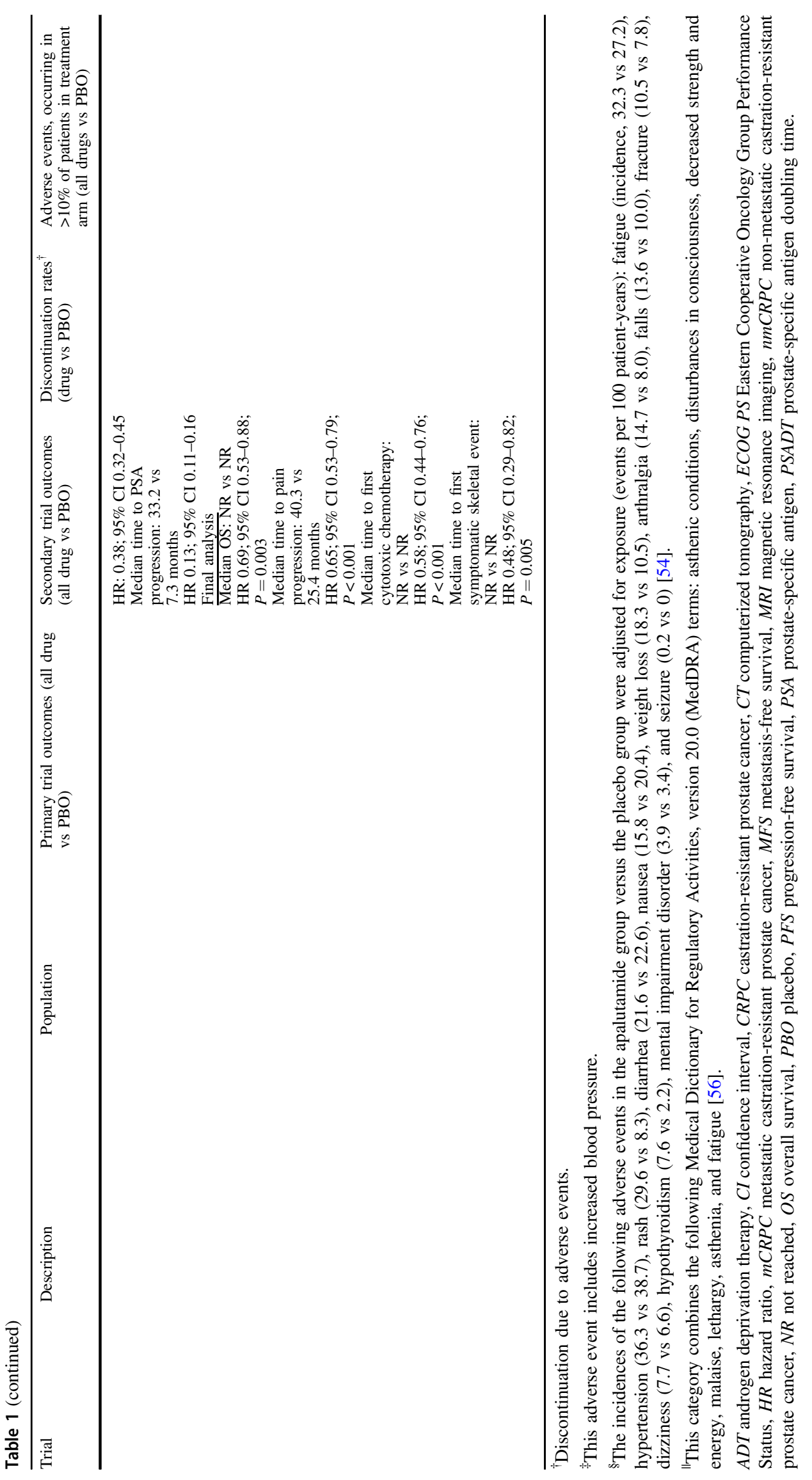




\section{Managing ARI-related AEs}

Aging itself may be associated with an increased fear of falling, which can promote restricted physical activity [66]. Exacerbated by a higher incidence of chronic comorbidities and long-term use of concomitant medication, immobility can further jeopardize physical function [67]. Thus, multiple, additive factors contribute to the therapeutic burden in the aging population of patients with PC.

Cancer-related fatigue is described as a "distressing" and "persistent" level of exhaustion related to cancer or cancer treatment that is not proportional to recent activity and interferes with usual functioning [68]. Patients experiencing fatigue have reported impaired ability to exercise, participate in productive employment, socialize, and perform daily living activities [68]. Regular exercise improves strength, maintains mobility, and balance, reduces the risk of falls, and attenuates symptoms of fatigue. Clinicians should encourage their patients to perform any amount or type of exercise at tolerable levels of intensity and/or duration [69-71].

Impaired cognitive function in patients with $\mathrm{PC}$ can complicate disease management and treatment decision-making, while impacting QoL and daily functioning. HCPs should be mindful of any pre-existing comorbidities, that may predispose the patient to further cognitive decline [72]. Furthermore, participating in group sessions that focus on improving memory skills, psychoeducation, and cognitive exercises can alleviate perceived symptoms of cognitive impairment that contribute to therapeutic burden and improve objective measures of attention and memory [73, 74].

Results from observational studies suggest that adherence to PC-specific diets may be associated with a decreased risk of disease progression [75]. Although patients have indicated that they would value dietary advice following a diagnosis of PC, HCPs have indicated that they do not routinely provide nutritional guidance as they may lack confidence in the dietary management of their patients with PC. HCPs should discuss aspects of nutrition and daily diet in the context of personalized disease management, notably in patients with comorbid conditions such as metabolic syndrome factors, diabetes, and obesity, which may adversely impact disease progression $[75,76]$.

\section{Potential for DDIs with second-generation ARIs}

As many patients with PC are older and may have comorbidities that require long-term, concomitant medication, it is important to consider the potential for DDIs between second-generation ARIs and comedications used in this population [35, 77]. Common comorbidities in patients with PC include hypercholesterolemia, hypertension, diabetes mellitus, asthma, urologic complications, depression, and neurologic disorders [78], with frequently reported comedications including antihypertensives and agents for other cardiovascular disorders, analgesics, treatments for urological and gastrointestinal disorders, antidepressants, anxiolytics, and anti-dementia drugs [79].

Both apalutamide and enzalutamide exhibit the potential for DDIs when co-administered with medications that are substrates for several metabolizing enzymes and drug transporters. Apalutamide and enzalutamide have been linked to the induction of cytochrome P450 (CYP) 3A4, $2 \mathrm{C} 9$, and $2 \mathrm{C} 19$ [80, 81]. These enzymes metabolize up to $50 \%$ of medications [82]. In a post hoc analysis of the SPARTAN trial, the risk of falls was increased in patients receiving apalutamide and concomitant alpha-blockers or antidepressants [83]. Apalutamide also has the potential to interact with uridine-diphosphate glucuronosyltransferase, P-glycoprotein (P-gp), breast cancer resistance protein (BCRP), and organic anion-transporting polypeptide (OATP) 1B1 [81], whereas enzalutamide might also interact with CYP2C8 inhibitors or inducers [80]. Consequently, in order to reduce the risk of DDIs, the respective prescribing information recommends that practitioners avoid simultaneous use of apalutamide or enzalutamide with these medications [80, 81]. Medicinal products that should be used with caution include antithrombotics, such as dabigatran; antihypertensives, such as amlodipine, statins such as rosuvastatin, and cardiac glycosides, such as digoxin [81].

Darolutamide has a molecular structure distinct from that of apalutamide and enzalutamide [65], and in its pivotal phase 3 trial only demonstrated a potential to interact with BCRP substrates and combined P-gp and CYP3A4 inducers or inhibitors [44, 79]. In preclinical and phase 1 studies, interaction of darolutamide with rosuvastatin, a substrate for the drug transporters BCRP and OATP, was the only clinically relevant interaction, which did not appear to translate into increased AEs in an analysis of safety data from the ARAMIS clinical trial [79, 84].

The risk of DDIs is an important consideration when selecting an AR-targeted therapy for patients with CRPC at risk for high therapeutic burden, and while DDIs may not translate to a clinically significant increase in treatmentrelated AEs, patients should continue to be monitored carefully for any increased risk of potential toxicities induced by these interactions. The loss of efficacy when coadministered with long-term medications or increased risk of drug-related adverse effects also represent clinically relevant outcomes of DDIs.

\section{Validated instruments for assessment of QoL}

Several validated assessment instruments and questionnaires have been developed to evaluate the impact of 
both disease and its treatment on physical and cognitive function in patients with PC. The choice of instrument may vary depending on whether the clinician intends to use it for screening symptoms or clinical research, and with which identifiable complaints the patient presents, e.g., the Functional Assessment of Cancer Therapy (FACT)-Cognitive tool explores different domains than the FACT-Prostate (FACT-P) tool (perceived cognitive function vs HRQoL). As various comorbidities and common complaints reported by patients with PC, e.g., fatigue and pain, may impact cognitive function, comprehensive assessment usually entails an evaluation of these symptoms. A lack of consensus prevails on the appropriate assessment instruments to apply to patients undergoing treatment for PC, particularly with respect to cognitive function $[85,86]$. Table 2 details the distinguishing features of some commonly used assessment tools.

When collecting patient-reported outcomes (PROs) in routine clinical practice, the underlying aims include identifying and managing symptoms, monitoring disease progression, and improving communication between patient and HCP. Although valuable, these aspirational goals may not always be achievable in "real-world practice". Clinicians often express reluctance to adopt validated assessment tools, preferring to obtain the same information by conversing with the patient in a less structured format and may lack appropriate training on the application of these instruments. For patients with PC, the length of the questionnaires and other assessment methods may pose an additional management burden. The extended consultation time required to complete these questionnaires may heighten patient anxiety and deter participation.

The use of electronic PRO (ePRO) systems should be considered to increase and improve data collection capabilities and options in clinical practice. ePRO systems may capture more complete and accurate data, improve protocol compliance, avoid data entry errors, and impose less administrative burden. Studies have reported that the use of ePRO systems resulted in survey completion rates of up to $90 \%$ in patients $[87,88]$.

Results from the ARAMIS, SPARTAN, and PROSPER trials have demonstrated similar trends in on-treatment $\mathrm{QoL}$ among patients with nmCRPC who are largely asymptomatic from their disease (Table 3). In SPARTAN, the leastsquares mean change from baseline showed that HRQoL deterioration was more apparent in the placebo group than in the apalutamide group [89]. In PROSPER, a trend favoring enzalutamide was observed for all domains of the FACT-P questionnaire with the exception of physical wellbeing [90], and in ARAMIS, darolutamide significantly delayed pain progression versus placebo $(40.3$ vs 25.4 months; hazard ratio [HR] $0.65 ; 95 \%$ confidence interval $[\mathrm{CI}] 0.53-0.79 ; P<0.001)$, which was maintained beyond end of study treatment [56]. In analyzing the FACTP PC-specific subscale (FACT-P PCS), change from baseline showed no clinically meaningful difference between darolutamide and placebo [56]. Time to deterioration of European Organisation for Research and Treatment of Cancer Quality of Life Questionnaire PC module (EORTC QLQ-PR25) outcomes demonstrated statistically and clinically significant delays with darolutamide versus placebo for urinary symptoms (25.8 vs 14.8 months; HR 0.64 ; $95 \%$ CI $0.54-0.76 ; P<0.01)$ [91].

\section{Validated instruments used in clinical practice}

The PRO questionnaires used in SPARTAN, PROSPER, and ARAMIS include some of the main PC-specific PROs adopted in clinical practice, including: the Expanded Prostate Cancer Index Composite-26 (EPIC-26), Expanded Prostate Cancer Index Composite-50 (EPIC-50), University of California-Los Angeles Prostate Cancer Index, FACT-P PCS, EORTC QLQ-PR25, Prostate Cancer-Quality of Life (PC-QoL), and Symptom Tracking and Reporting (STAR) [92].

These instruments focus on the subjective impact of physical aspects of health, with fewer items capturing the perceived impact of mental health. The EPIC-26, EPIC-50, and PC-QoL include the greatest number of items that can be labeled as "QoL". Most of these items reflect the subjective impact of physical aspects of health, such as urinary symptoms or changes in weight. Items that capture the subjective impact of social aspects of health were less common. Although the PC-QoL included items that alluded to the impact of mental aspects of health, there was only one item about "worry" arising from the ability to sexually please a partner and categorized as an aspect of social health [92]. As these gaps in assessment domains may compromise the validity of the six instruments as well as the respective interpretation of scores and suitability for application in "real-world" patient evaluations, the true impact of PC treatment may not be conveyed via currently available HRQoL outcomes measures [92].

\section{Conclusions and future directions}

The treatment landscape in PC is evolving rapidly, with three, second-generation ARIs available for management across the various types and stages of disease. Apalutamide, enzalutamide, and darolutamide have proven efficacious in prolonging OS, extending MFS, and demonstrating positive trends in PFS [50, 54, 56]. An important clinical consideration concerns the balance between therapeutic benefits and potential AEs that may be further complicated by DDIs with chronically administered, concomitant medications. 


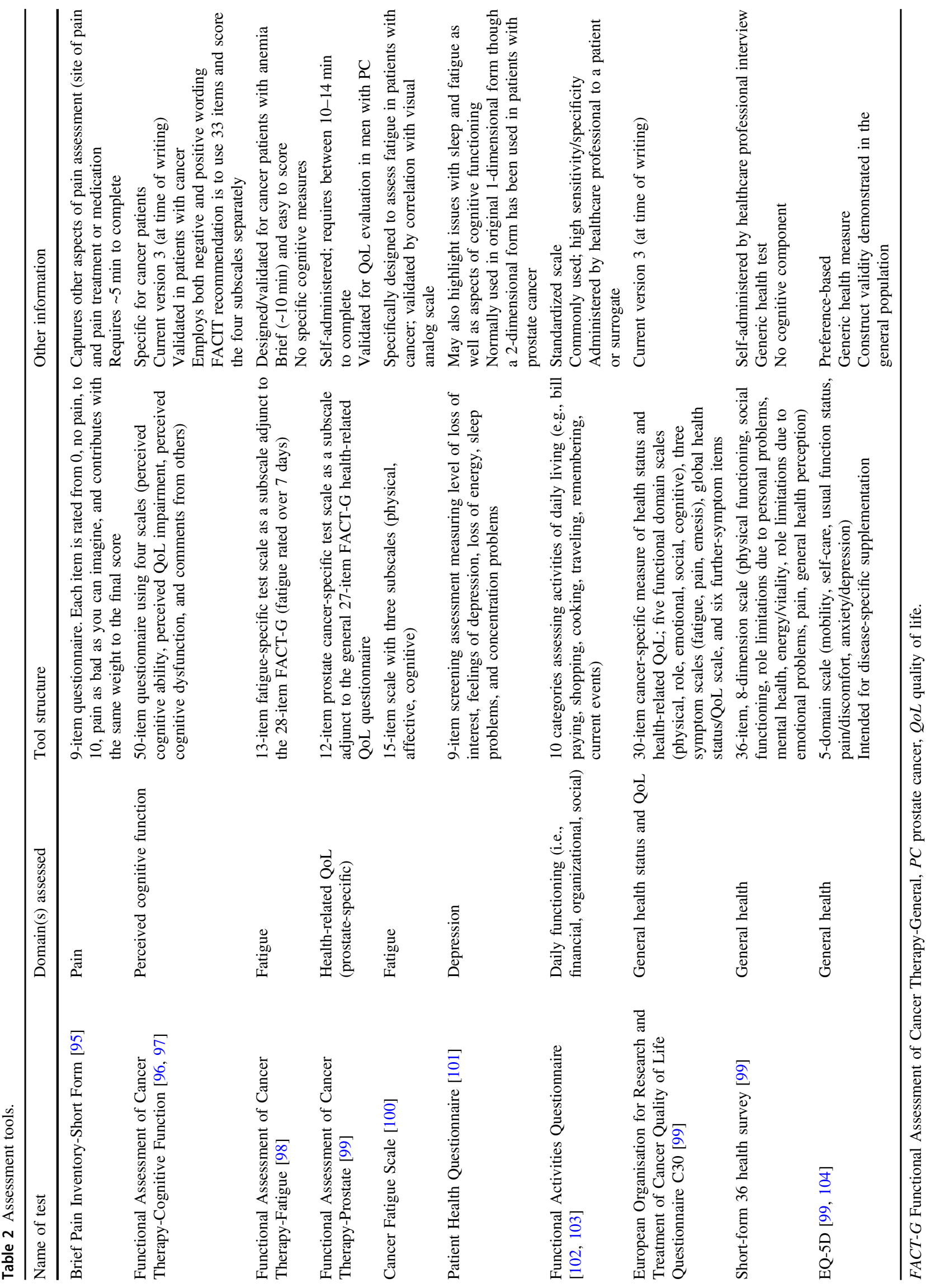




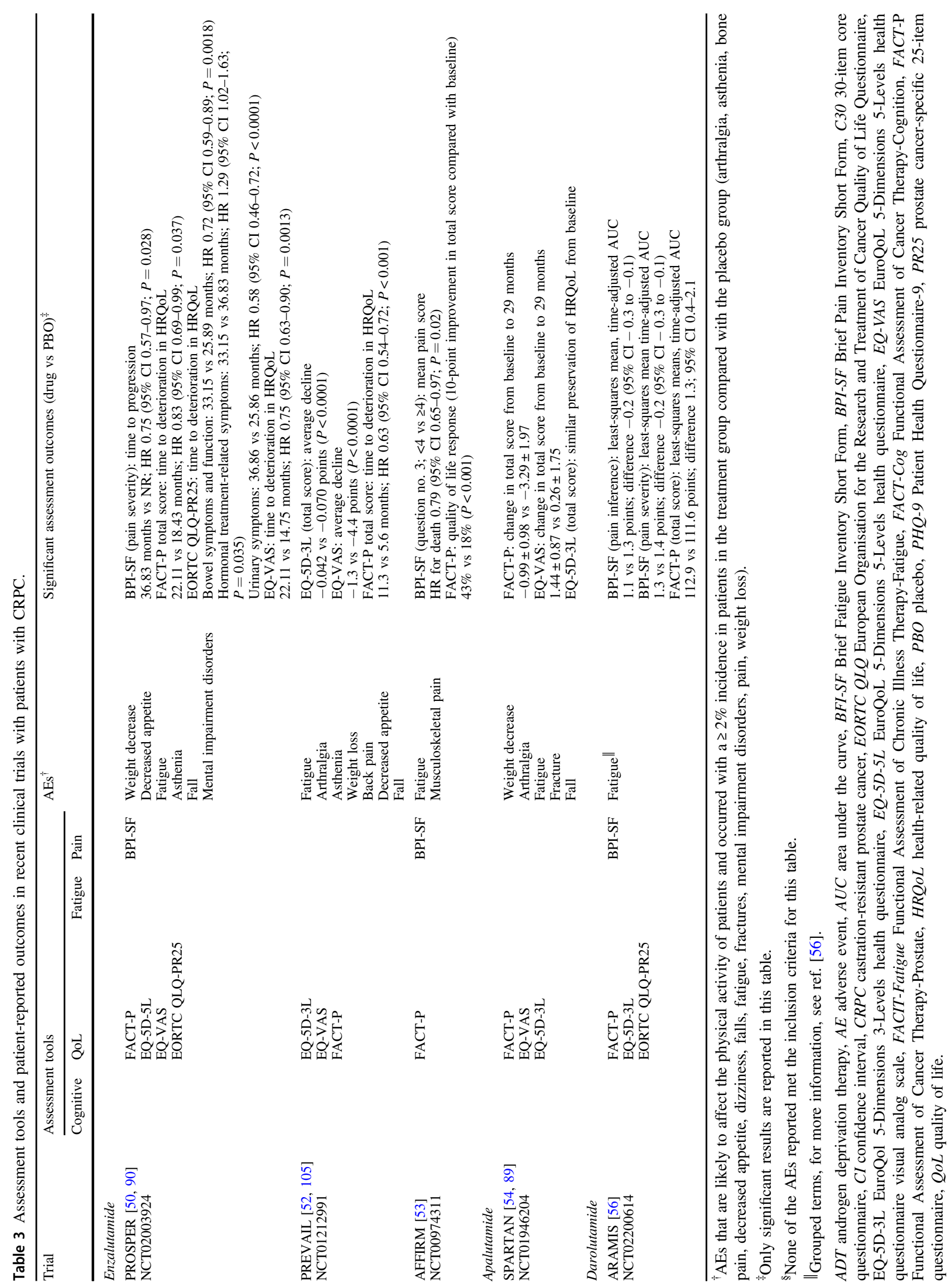


Although second-generation ARIs demonstrate acceptable tolerability profiles in patients with CRPC, their individual drug safety and pharmacologic profiles should be considered prior to initiating combined therapy with continuous ADT. Future studies should consider the impact of chronic comorbidities on MFS, OS, and QoL. There is also a need for expert guidance on addressing common DDIs at the community practice level, especially in the absence of a clinical pharmacist.

Patient-centered communication represents a critical step toward alleviating therapeutic burden [19]. The importance of prompt and frequent updates to the history of onset and/ or exacerbation of symptoms and the changes in ontreatment versus baseline activity levels should be highlighted during physician training. Close monitoring of therapeutic response over time affords HCPs the opportunity to better understand symptom onset and exacerbation in the context of an appropriately individualized treatment regimen. Healthcare providers should consider offering suggestions for preventive measures that may encourage older, comorbid patients treated for PC to participate in support groups, exercise as tolerated, and enroll in physical therapy and/or patient education programs [69-71, 73, 74]. As the financial burden of PC impacts not only the individual but also the overall healthcare system, it is important that the HCP serve as the interface between health insurers and the practice site, assuming the role of frontline patient advocate [28].

Practical approaches that enable sensitive evaluation of factors that constitute a therapeutic burden to the patient with CRPC should be incorporated into routine clinical practice to help ensure that treatment efficacy, maintenance of physical and cognitive function, and preserved QoL are considered on an individualized basis. In particular, the transition to ePRO systems should be made to help improve accuracy when collecting QoL information, as well as to alleviate the administrative burden.

Acknowledgements Medical writing support was provided by Farzana Miah, MSc, of Scion, London, UK. Editorial support, including referencing, and proofreading was provided by Annabel Ola, MSc, of Scion, London, UK. All medical writing and editorial services were funded by Bayer HealthCare Pharmaceuticals, Inc. (Whippany, NJ, USA) according to Good Publication Practice guidelines (Link). However, the ultimate responsibility for opinions, conclusions, and data interpretation lies with the authors.

\section{Compliance with ethical standards}

Conflict of interest DS has received grants from Janssen and personal fees from Janssen, Blue Earth, and AstraZeneca. NS has received personal fees from Amgen, Astellas, AstraZeneca, Bristol-Myers Squibb, Bayer, Dendreon, Ferring, Fergene, Janssen, Merck, Myovant, Nymox, Pfizer, Sanofi, Tolmar, Boston Scientific, and MDx Health. OS has received personal fees from AAA, Astellas, AstraZeneca, Bayer, Blue Earth diagnostics, Bravarin Nordic, Bristol-Myers Squibb,
Clovis, Constellation, Dendreon, EMD Serono, Endocyte, Pfizer, Progenics, Sanofi, Merck, Myriad, Noria Therapeutics, Noxopaharm, Point Biopharma, Tenebio, Theragnostics, Telix, Clarity Pharmaceuticals, Novartis, and Janssen, and has received grants from AAA, AstraZeneca, Bayer, Endocyte, Progenics, Sanofi, Innocrin, Invitae, Merck, Novartis, Sotio and Janssen. KO reports consulting for Exelixis. DR declares no conflict of interest.

Publisher's note Springer Nature remains neutral with regard to jurisdictional claims in published maps and institutional affiliations.

Open Access This article is licensed under a Creative Commons Attribution 4.0 International License, which permits use, sharing, adaptation, distribution and reproduction in any medium or format, as long as you give appropriate credit to the original author(s) and the source, provide a link to the Creative Commons license, and indicate if changes were made. The images or other third party material in this article are included in the article's Creative Commons license, unless indicated otherwise in a credit line to the material. If material is not included in the article's Creative Commons license and your intended use is not permitted by statutory regulation or exceeds the permitted use, you will need to obtain permission directly from the copyright holder. To view a copy of this license, visit http://creativecommons. org/licenses/by/4.0/.

\section{References}

1. United Nations. World population ageing 2019: highlights. https://www.un.org/en/development/desa/population/publica tions/pdf/ageing/WorldPopulationAgeing2019-Highlights.pdf. Accessed April 17, 2020.

2. Orimo H. [Reviewing the definition of elderly]. Nihon Ronen Igakkai Zasshi 2006;43:27-34.

3. Singh S, Bajorek B. Defining 'elderly' in clinical practice guidelines for pharmacotherapy. Pharm Pract (Granada) 2014;12:489-89.

4. Levine ME. Modeling the rate of senescence: can estimated biological age predict mortality more accurately than chronological age? J Gerontol Ser A, Biol Sci Med Sci 2013;68:667-74.

5. Salinas CA, Tsodikov A, Ishak-Howard M, Cooney KA. Prostate cancer in young men: an important clinical entity. Nat Rev Urol 2014;11:317-23.

6. Alibhai SM, Krahn MD, Fleshner NE, Cohen MM, Tomlinson GA, Naglie G. The association between patient age and prostate cancer stage and grade at diagnosis. BJU Int 2004;94:303-6.

7. Pettersson A, Robinson D, Garmo H, Holmberg L, Stattin P. Age at diagnosis and prostate cancer treatment and prognosis: a population-based cohort study. Ann Oncol 2017;29:377-85.

8. Jones CU, Hunt D, McGowan DG, Amin MB, Chetner MP, Bruner DW, et al. Radiotherapy and short-term androgen deprivation for localized prostate cancer. N. Engl J Med 2011;365:107-18.

9. Bray F, Ferlay J, Soerjomataram I, Siegel RL, Torre LA, Jemal A. Global cancer statistics 2018: GLOBOCAN estimates of incidence and mortality worldwide for 36 cancers in 185 countries. CA Cancer J Clin 2018;68:394-424.

10. Rawla P. Epidemiology of prostate cancer. World J Oncol 2019;10:63-89.

11. American Cancer Society. Cancer facts \& figures 2020. https://www.cancer.org/content/dam/cancer-org/research/cancerfacts-and-statistics/annual-cancer-facts-and-figures/2020/cancerfacts-and-figures-2020.pdf. Accessed April 20, 2020.

12. Mottet N, van den Bergh RCN, Briers E, Cornford P, De Santis M, Fanti S, et al. EAU - EANM - ESTRO - ESUR - SIOG 
guidelines on prostate cancer. https://uroweb.org/guideline/ prostate-cancer/. Accessed May 7, 2020.

13. Luo J, Beer TM, Graff JN. Treatment of nonmetastatic castration-resistant prostate cancer. Oncology 2016;30:336-44.

14. Coutinho I, Day TK, Tilley WD, Selth LA. Androgen receptor signaling in castration-resistant prostate cancer: a lesson in persistence. Endocr Relat Cancer 2016;23:T179-T97.

15. Eton DT, Ramalho de Oliveira D, Egginton JS, Ridgeway JL, Odell L, May CR, et al. Building a measurement framework of burden of treatment in complex patients with chronic conditions: a qualitative study. Patient Relat Outcome Meas 2012;3: 39-49.

16. Gallacher K, May CR, Montori VM, Mair FS. Understanding patients' experiences of treatment burden in chronic heart failure using normalization process theory. Ann Fam Med 2011;9: 235-43.

17. May C, Montori VM, Mair FS. We need minimally disruptive medicine. Br Med J 2009;339:b2803.

18. Committee on Improving the Quality of Cancer Care: Addressing the challenges of an aging population, Board on Health Care Services, Institute of Medicine. In: Levit L, Balogh E, Nass S, Ganz PA (eds). Delivering high-quality cancer care: charting $a$ new course for a system in crisis. National Academies Press (US): Washington (DC), 2013.

19. Ernstmann N, Herden J, Weissbach L, Karger A, Hower K, Ansmann L. Prostate-specific health-related quality of life and patient-physician communication - a 3.5-year follow-up. Patient Educ Couns 2019;102:2114-21.

20. Ayanian JZ, Zaslavsky AM, Guadagnoli E, Fuchs CS, Yost KJ, Creech CM, et al. Patients' perceptions of quality of care for colorectal cancer by race, ethnicity, and language. J Clin Oncol 2005;23:6576-86.

21. Freeman HP, Reuben SH. Voices of a broken system: real people, real problems. President's Cancer Panel Report of the Chairman. 2000;2001.

22. Lee CN, Chang Y, Adimorah N, Belkora JK, Moy B, Partridge $\mathrm{AH}$, et al. Decision making about surgery for early-stage breast cancer. J Am Coll Surg 2012;214:1-10.

23. Zikmund-Fisher BJ, Couper MP, Singer E, Ubel PA, Ziniel S, Fowler FJ Jr., et al. Deficits and variations in patients' experience with making 9 common medical decisions: the DECISIONS survey. Med Decis Mak 2010;30:85s-95s.

24. Geng H-M, Chuang D-M, Yang F, Yang Y, Liu W-M, Liu L-H, et al. Prevalence and determinants of depression in caregivers of cancer patients: a systematic review and meta-analysis. Medicine 2018;97:e11863.

25. Harden JK, Sanda MG, Wei JT, Yarandi H, Hembroff L, Hardy J, et al. Partners' long-term appraisal of their caregiving experience, marital satisfaction, sexual satisfaction, and quality of life 2 years after prostate cancer treatment. Cancer Nurs 2013;36:104-13.

26. Sambasivam R, Liu J, Vaingankar JA, Ong HL, Tan ME, Fauziana $\mathrm{R}$, et al. The hidden patient: chronic physical morbidity, psychological distress, and quality of life in caregivers of older adults. Psychogeriatrics 2019;19:65-72.

27. Ritchie CS, Kvale E, Fisch MJ. Multimorbidity: an issue of growing importance for oncologists. J Oncol Pract 2011;7: $371-4$.

28. Carrera PM, Kantarjian HM, Blinder VS. The financial burden and distress of patients with cancer: understanding and steppingup action on the financial toxicity of cancer treatment. CA Cancer J Clin 2018;68:153-65.

29. de Souza JA, Yap BJ, Wroblewski K, Blinder V, Araujo FS, Hlubocky FJ, et al. Measuring financial toxicity as a clinically relevant patient-reported outcome: the validation of the COmprehensive Score for financial Toxicity (COST). Cancer 2017;123:476-84.
30. Catt S, Starkings R, Shilling V, Fallowfield L. Patient-reported outcome measures of the impact of cancer on patients' everyday lives: a systematic review. J Cancer Surviv 2017;11:211-32.

31. Stokes ME, Ishak J, Proskorovsky I, Black LK, Huang Y. Lifetime economic burden of prostate cancer. BMC Health Serv Res 2011;11:349.

32. Sanyal C, Aprikian AG, Chevalier S, Cury FL, Dragomir A. Direct cost for initial management of prostate cancer: a systematic review. Curr Oncol 2013;20:e522-31.

33. Raval AD, Madhavan S, Mattes MD, Sambamoorthi U. Association between types of chronic conditions and cancer stage at diagnosis among elderly Medicare beneficiaries with prostate cancer. Popul Health Manag 2016;19:445-53.

34. Walker V, Perret-Guillaume C, Kesse-Guyot E, Agrinier N, Hercberg S, Galan P, et al. Effect of multimorbidity on healthrelated quality of life in adults aged 55 years or older: results from the SU.VI.MAX 2 cohort. PLoS ONE 2016;11: e0169282.

35. Droz JP, Albrand G, Gillessen S, Hughes S, Mottet N, Oudard S, et al. Management of prostate cancer in elderly patients: recommendations of a task force of the International Society of Geriatric Oncology. Eur Urol 2017;72:521-31.

36. Wefel JS, Vardy J, Ahles T, Schagen SB. International cognition and cancer task force recommendations to harmonise studies of cognitive function in patients with cancer. Lancet Oncol 2011;12:703-08.

37. Chiumento C, Fiorentino A, Cozzolino M, Caivano R, Clemente $\mathrm{S}$, Pedicini $\mathrm{P}$, et al. Impact of comorbidity in elderly prostate cancer patients treated with brachytherapy. Chin J Cancer Res 2013;25:274-80.

38. Wei MY, Kawachi I, Okereke OI, Mukamal KJ. Diverse cumulative impact of chronic diseases on physical health-related quality of life: implications for a measure of multimorbidity. Am J Epidemiol 2016;184:357-65.

39. Chandrasekar T, Yang JC, Gao AC, Evans CP. Mechanisms of resistance in castration-resistant prostate cancer (CRPC). Transl Androl Urol 2015;4:365-80.

40. Heinlein CA, Chang C. Androgen receptor in prostate cancer. Endocr Rev 2004;25:276-308.

41. Janssen Ortho LLC ZYTIGA (abiraterone acetate) US prescribing information. http://www.janssenlabels.com/package-insert/ product-monograph/prescribing-information/ZYTIGA-pi.pdf. Accessed July 22, 2019.

42. Rathkopf D, Scher HI. Androgen receptor antagonists in castration-resistant prostate cancer. Cancer J 2013;19:43-9.

43. Astellas Pharma US Inc. Xtandi (enzalutamide) US prescribing information. https://www.accessdata.fda.gov/drugsatfda_docs/la bel/2018/203415s014lbl.pdf. Accessed June 11, 2019.

44. Bayer HealthCare Pharmaceuticals Inc. Nubeqa (darolutamide) US prescribing information. https://www.accessdata.fda.gov/ drugsatfda_docs/label/2019/212099Orig1s000lbl.pdf. Accessed December 13, 2019.

45. Food and Drug Administration. Prescribing information: ERLEADA. https://www.accessdata.fda.gov/drugsatfda_docs/la bel/2018/210951s000lbl.pdf. Accessed June 11, 2019.

46. Gul A, Garcia JA, Barata PC. Treatment of non-metastatic castration-resistant prostate cancer: focus on apalutamide. Cancer Manag Res 2019;11:7253-62.

47. McKay RR, Ye H, Xie W, Lis R, Calagua C, Zhang Z, et al. Evaluation of intense androgen deprivation before prostatectomy: a randomized phase II trial of enzalutamide and leuprolide with or without abiraterone. $\mathrm{J}$ Clin Oncol 2019;37:923-31.

48. Ryan C, Wefel JS, Morgans AK. A review of prostate cancer treatment impact on the CNS and cognitive function. Prostate Cancer Prostatic Dis 2020;23:207-19. 
49. Nguyen PL, Alibhai SM, Basaria S, D’Amico AV, Kantoff PW, Keating NL, et al. Adverse effects of androgen deprivation therapy and strategies to mitigate them. Eur Urol 2015;67: 825-36.

50. Hussain M, Fizazi K, Saad F, Rathenborg P, Shore N, Ferreira U, et al. Enzalutamide in men with nonmetastatic, castrationresistant prostate cancer. N Engl J Med 2018;378:2465-74.

51. Sternberg CN, Fizazi K, Saad F, Shore ND, De Giorgi U, Penson $\mathrm{DF}$, et al. Enzalutamide and survival in nonmetastatic, castrationresistant prostate cancer. N. Engl J Med 2020;382:2197-206.

52. Beer TM, Tombal B. Enzalutamide in metastatic prostate cancer before chemotherapy. N. Engl J Med 2014;371:1755-6.

53. Scher HI, Fizazi K, Saad F, Taplin ME, Sternberg CN, Miller K, et al. Increased survival with enzalutamide in prostate cancer after chemotherapy. N. Engl J Med 2012;367:1187-97.

54. Smith MR, Saad F, Chowdhury S, Oudard S, Hadaschik BA, Graff JN, et al. Apalutamide treatment and metastasis-free survival in prostate cancer. N. Engl J Med 2018;378:1408-18.

55. Smith MR, Saad F, Chowdhury S, Oudard S, Hadaschik BA, Graff JN, et al. Apalutamide and overall survival in prostate cancer. Eur Urol. 2021; 79:150-158.

56. Fizazi K, Shore N, Tammela TL, Ulys A, Vjaters E, Polyakov S, et al. Darolutamide in nonmetastatic, castration-resistant prostate cancer. N. Engl J Med 2019;380:1235-46.

57. Fizazi K, Shore N, Tammela TL, Ulys A, Vjaters E, Polyakov S, et al. Nonmetastatic, castration-resistant prostate cancer and survival with darolutamide. N. Engl J Med 2020;383:1040-49.

58. Mateo J, Fizazi K, Gillessen S, Heidenreich A, Perez-Lopez R, Oyen WJG, et al. Managing nonmetastatic castration-resistant prostate cancer. Eur Urol 2019;75:285-93.

59. Graff JN, Baciarello G, Armstrong AJ, Higano CS, Iversen P, Flaig TW, et al. Efficacy and safety of enzalutamide in patients 75 years or older with chemotherapy-naive metastatic castrationresistant prostate cancer: results from PREVAIL. Ann Oncol 2016;27:286-94.

60. Pilon D, Behl AS, Ellis LA, Robitaille MN, Lefebvre P, Dawson NA. Assessment of real-world central nervous system events in patients with advanced prostate cancer using abiraterone acetate, bicalutamide, enzalutamide, or chemotherapy. Am Health Drug Benefits 2017;10:143-53.

61. Scher HI, Beer TM, Higano CS, Anand A, Taplin ME, Efstathiou E, et al. Antitumour activity of MDV3100 in castrationresistant prostate cancer: a phase 1-2 study. Lancet 2010;375: 1437-46.

62. Williams S, Mazibuko N, O’Daly O, Zurth C, Patrick F, Woolridge C, et al. Significant localized reduction in cerebral blood flow $(\mathrm{CBF})$ in regions relevant to cognitive function with enzalutamide (ENZA) compared to darolutamide (DARO) and placebo (PBO) in healthy volunteers. J Clin Oncol 2020;38:abstr 326.

63. Sandmann S, Trummel D, Seidel D, Nubbemeyer R, Gieschen $\mathrm{H}$, Zurth C Higher blood-brain barrier penetration of [14C]apalutamide and [14C]enzalutamide compared to [14C]darolutamide in rats using whole-body autoradiography. ASCO Genitourinary Cancers Symposium; 14-16 February; San Francisco.

64. Zurth C, Sandmann S, Trummel D, Seidel D, Gieschen H. Blood-brain barrier penetration of [14C]darolutamide compared with [14C]enzalutamide in rats using whole body autoradiography. J Clin Oncol 2018;36:345.

65. Moilanen AM, Riikonen R, Oksala R, Ravanti L, Aho E, Wohlfahrt G, et al. Discovery of ODM-201, a new-generation androgen receptor inhibitor targeting resistance mechanisms to androgen signaling-directed prostate cancer therapies. Sci Rep. 2015;5:12007.

66. van Haastregt JC, Zijlstra GA, van Rossum E, van Eijk JT, Kempen GI. Feelings of anxiety and symptoms of depression in community-living older persons who avoid activity for fear of falling. Am J Geriatr Psychiatry 2008;16:186-93.

67. Galvao DA, Taaffe DR, Spry N, Joseph D, Turner D, Newton RU. Reduced muscle strength and functional performance in men with prostate cancer undergoing androgen suppression: a comprehensive cross-sectional investigation. Prostate Cancer Prostatic Dis 2009;12:198-203.

68. Network NCC. National Comprehensive Cancer Network clinical practice guidelines in oncology: cancer-related fatigue. https://www.nccn.org/professionals/physician_gls/pdf/fatigue. pdf. Accessed July 6, 2020.

69. Galvao DA, Taaffe DR, Spry N, Newton RU. Exercise can prevent and even reverse adverse effects of androgen suppression treatment in men with prostate cancer. Prostate Cancer Prostatic Dis 2007;10:340-6.

70. Taaffe DR, Newton RU, Spry N, Joseph D, Chambers SK, Gardiner RA, et al. Effects of different exercise modalities on fatigue in prostate cancer patients undergoing androgen deprivation therapy: a year-long randomised controlled trial. Eur Urol 2017;72:293-99.

71. Winters-Stone KM, Dobek JC, Bennett JA, Dieckmann NF, Maddalozzo GF, Ryan CW, et al. Resistance training reduces disability in prostate cancer survivors on androgen deprivation therapy: evidence from a randomized controlled trial. Arch Phys Med Rehabil 2015;96:7-14.

72. Joly F, Giffard B, Rigal O, De Ruiter MB, Small BJ, Dubois M, et al. Impact of cancer and its treatments on cognitive function: advances in research from the Paris International Cognition and Cancer Task Force symposium and update since 2012. J Pain Symptom Manag 2015;50:830-41.

73. Cherrier MM, Anderson K, David D, Higano CS, Gray H, Church A, et al. A randomized trial of cognitive rehabilitation in cancer survivors. Life Sci 2013;93:617-22.

74. Ercoli LM, Petersen L, Hunter AM, Castellon SA, Kwan L, Kahn-Mills BA, et al. Cognitive rehabilitation group intervention for breast cancer survivors: results of a randomized clinical trial. Psychooncology 2015;24:1360-7.

75. Sutton E, Hackshaw-McGeagh LE, Aning J, Bahl A, Koupparis A, Persad R, et al. The provision of dietary and physical activity advice for men diagnosed with prostate cancer: a qualitative study of the experiences and views of health care professionals, patients and partners. Cancer Causes Control 2017;28:319-29.

76. Kaiser A, Haskins C, Siddiqui MM, Hussain A, D'Adamo C. The evolving role of diet in prostate cancer risk and progression. Curr Opin Oncol 2019;31:222-29.

77. Li H, Hodgson E, Watson L, Shukla A, Nelson JJ. Comorbidities and concomitant medication use in men with prostate cancer or high levels of PSA compared to matched controls: a GPRD analysis. J Cancer Epidemiol 2012;2012:291704.

78. Fleshner K, Tin A, Benfante N, Carlsson S, Vickers AJ. Comparison of physician-documented versus patient-reported collection of comorbidities among patients with prostate cancer upon first visit to the urology clinic. JCO Clin Cancer Inform 2018;2:1-10.

79. Shore N, Zurth C, Fricke R, Gieschen H, Graudenz K, Koskinen $\mathrm{M}$, et al. Evaluation of clinically relevant drug-drug interactions with darolutamide in the phase 3 ARAMIS trial for patients with nonmetastatic castration-resistant prostate cancer. Target Oncol 2019;14:527-39.

80. Astellas. Xtandi prescribing information. https://www.accessda ta.fda.gov/drugsatfda_docs/label/2018/203415s014lbl.pdf. Accessed September 26, 2018.

81. Janssen Ortho LLC. Erleada (apalutamide) US prescribing information. Revised 09/2020. http://www.janssenlabels.com/pa ckage-insert/product-monograph/prescribing-information/ ERLEADA-pi.pdf. Accessed October 21, 2020. 
82. Del Re M, Fogli S, Derosa L, Massari F, De Souza P, Crucitta S, et al. The role of drug-drug interactions in prostate cancer treatment: focus on abiraterone acetate/prednisone and enzalutamide. Cancer Treat Rev 2017;55:71-82.

83. Pollock Y, Smith M, Saad F, Chowdhury S, Oudard S, Hadaschik B, et al. Predictors of falls and fractures in patients (pts) with nonmetastatic castration-resistant prostate cancer (nmCRPC) treated with apalutamide (APA) plus ongoing androgen deprivation therapy (ADT). J Clin Oncol 2019;37:5025.

84. Zurth C, Koskinen M, Fricke R, Prien O, Korjamo T, Graudenz $\mathrm{K}$, et al. Drug-drug interaction potential of darolutamide: in vitro and clinical studies. Eur J Drug Metab Pharmacokinet 2019;44:747-59.

85. Nelson CJ, Lee JS, Gamboa MC, Roth AJ. Cognitive effects of hormone therapy in men with prostate cancer: a review. Cancer 2008;113:1097-106.

86. Treanor CJ, Li J, Donnelly M. Cognitive impairment among prostate cancer patients: an overview of reviews. Eur J Cancer Care 2017;26:e12642.

87. Coons SJ, Eremenco S, Lundy JJ, O’Donohoe P, O'Gorman H, Malizia W. Capturing patient-reported outcome (PRO) data electronically: the past, present, and promise of ePRO measurement in clinical trials. Patient 2015;8:301-09.

88. Lucas SM, Kim TK, Ghani KR, Miller DC, Linsell S, Starr J, et al. Establishment of a web-based system for collection of patientreported outcomes after radical prostatectomy in a statewide quality improvement collaborative. Urology 2017;107:96-102.

89. Saad F, Cella D, Basch E, Hadaschik BA, Mainwaring PN, Oudard S, et al. Effect of apalutamide on health-related quality of life in patients with non-metastatic castration-resistant prostate cancer: an analysis of the SPARTAN randomised, placebocontrolled, phase 3 trial. Lancet Oncol 2018;19:1404-16.

90. Tombal B, Saad F, Penson D, Hussain M, Sternberg CN, Morlock R, et al. Patient-reported outcomes following enzalutamide or placebo in men with non-metastatic, castration-resistant prostate cancer (PROSPER): a multicentre, randomised, double-blind, phase 3 trial. Lancet Oncol 2019;20:556-69.

91. Fizazi K, Shore ND, Tammela T, Kuss I, Le Berre MA, Mohamed AF, et al. Impact of darolutamide (DARO) on pain and quality of life (QoL) in patients (Pts) with nonmetastatic castrate-resistant prostate cancer (nmCRPC). ASCO; May 31-June 4; Chicago, USA.

92. Protopapa E, van der Meulen J, Moore CM, Smith SC. Patientreported outcome (PRO) questionnaires for men who have radical surgery for prostate cancer: a conceptual review of existing instruments. BJU Int 2017;120:468-81.

93. Small EJ, Saad F, Chowdhury S, Oudard S, Hadaschik BA, Graff JN, et al. Final survival results from SPARTAN, a phase III study of apalutamide (APA) versus placebo (PBO) in patients (pts) with nonmetastatic castration-resistant prostate cancer (nmCRPC). J Clin Oncol 2020;38:abstr 5516.

94. Fizazi K, Shore ND, Tammela T, Ulys A, Vjaters E, Polyakov S, et al. Overall survival (OS) results of phase III ARAMIS study of darolutamide (DARO) added to androgen deprivation therapy (ADT) for nonmetastatic castration-resistant prostate cancer (nmCRPC). J Clin Oncol 2020;38:abstr 5514.

95. Poquet N, Lin C. The Brief Pain Inventory (BPI). J Physiother 2016;62:52.

96. Marzouk S, Naglie G, Tomlinson G, Duff Canning S, Breunis H, Timilshina $\mathrm{N}$, et al. Impact of androgen deprivation therapy on self-reported cognitive function in men with prostate cancer. J Urol 2018;200:327-34.

97. Von Ah D, Jansen CE, Allen DH. Evidence-based interventions for cancer- and treatment-related cognitive impairment. Clin J Oncol Nurs 2014;18(Suppl):17-25.

98. Yellen SB, Cella DF, Webster K, Blendowski C, Kaplan E. Measuring fatigue and other anemia-related symptoms with the Functional Assessment of Cancer Therapy (FACT) measurement system. J Pain Symptom Manag 1997;13:63-74.

99. Morris C, Gibbons E, Fitzpatrick R Patient reported outcome measures. http://phi.uhce.ox.ac.uk/pdf/CancerReviews/PROMs Oxford_Prostate\%20Cancer_012011.pdf. Accessed December $18,2018$.

100. Okuyama T, Akechi T, Kugaya A, Okamura H, Shima Y, Maruguchi M, et al. Development and validation of the cancer fatigue scale: a brief, three-dimensional, self-rating scale for assessment of fatigue in cancer patients. J Pain Symptom Manag 2000;19:5-14.

101. Hinz A, Mehnert A, Kocalevent RD, Brähler E, Forkmann T, Singer S, et al. Assessment of depression severity with the PHQ9 in cancer patients and in the general population. BMC Psychiatry. 2016;16:22.

102. Teng E, Becker BW, Woo E, Knopman DS, Cummings JL, Lu $\mathrm{PH}$. Utility of the functional activities questionnaire for distinguishing mild cognitive impairment from very mild Alzheimer's disease. Alzheimer Dis Assoc Disord 2010;24:348-53.

103. Marshall GA, Zoller AS, Lorius N, Amariglio R, Locascio J, Johnson K, et al. Functional activities questionnaire items that best discriminate and predict progression from clinically normal to mild cognitive impairment. Curr Alzheimer Res 2015;12: 493-502.

104. Pickard AS, Ray S, Ganguli A, Cella D. Comparison of FACTand EQ-5D-based utility scores in cancer. Value Health 2012;15:305-11.

105. Devlin N, Herdman M, Pavesi M, Phung, Naidoo S, Beer TM, et al. Health-related quality of life effects of enzalutamide in patients with metastatic castration-resistant prostate cancer: an in-depth post hoc analysis of EQ-5D data from the PREVAIL trial. Health Qual Life Outcomes 2017;15:130. 